\title{
Linguagem e Responsabilidade: Contribuições de J. Eagle para Relacionamentos Saudáveis
}

\author{
Cláudia Maria Moura Pierre
}

Resumo: Jake Eagle propõe um modo de ser em que assumimos total responsabilidade por nossos sentimentos, percepções e atitudes, que fomenta relacionamentos harmoniosos. Ao assumir a responsabilidade por nossa vida, deixamos de culpar os outros, que é o fator que gera conflitos. Esta atitude é resultado da assunção de que nossa percepção somos nós que erigimos; nós que damos ao mundo o significado que ele tem. Ele fundamenta isto considerando como acontece o processo perceptivo. Há uma gama estímulos que chegam até o sistema sensório. Mas, cada um tem filtros perceptivos próprios. Isto implica na responsabilidade pelo que vemos. A partir disso, ele propõe uma mudança na maneira como nos posicionamos perante os acontecimentos. Também, sugere uma maneira de se comunicar em que fica explícito que o mundo que estamos falando é o mundo que percebemos. Para Eagle, a forma que conversamos conosco e com outras pessoas determina a qualidade de nossos relacionamentos.

Palavras-chave: Percepção, Relacionamento, Responsabilidade, Linguagem.

\section{Language and Responsibility: J. Eagle's Contribution to Healthy Relationships}

\begin{abstract}
Jake Eagle proposes a way of being in which we take full responsibility for our feelings, perceptions and attitudes, which helps creating harmonious relationships. By taking responsibility for our lives, we stop blaming others, which is the factor that fosters conflict. This attitude is the result of the assumption that our perception is engendered by ourselves, we give the world the meaning it has for us. He bases this considering how the perceptual process happens. There are a range stimuli that reach the sensory system, but each one of us have our own perceptual filter. This implies the responsibility for what we see. Because of this, he proposes a change in the way we position ourselves toward events. He also suggests a way to communicate that is explicitly stated that the world we're talking about is the world we perceive. For Eagle, the way we talk with ourselves and with others determines the quality of our relationships.
\end{abstract}

Key Words: Perception, Relationships, Responsibility, Language.

\section{Introdução}

Jake Eagle é um psicoterapeuta americano e propõe um modo de ser e estar no mundo, em que assumimos total responsabilidade por nossos sentimentos e percepções, de modo que ajuda a criar relacionamentos mais harmoniosos.

Ao assumir a responsabilidade por nossos sentimentos e comportamentos, deixamos de jogar culpa nos outros, fator que fomenta conflitos. Esta nova atitude frente ao mundo é resultado do assunção de que nossa percepção de mundo somos nós que erigimos.

O fundamento reside no reconhecimento de como acontece o processo perceptivo. Para este psicoterapeuta, há uma gama de inputs, que são os estímulos que chegam até nosso sistema sensório. Mas cada um de nós tem filtros perceptivos que ele chama de percept screen - tela perceptiva.

\footnotetext{
${ }^{1}$ Cientista Social com Mestrado em Sociologia e Doutoranda em Educação. Professora Adjunta da Universidade Regional do Cariri URCA. E-mail: claudiampierre@gmail.com.
} 
Os filtros pessoais são erigidos a partir dos genes, família, cultura, origem étnica, educação, religião, capacidades, crenças, estados de espírito, necessidades, gênero, ambições, idade, expectativas, valores etc. São estes filtros que vão formatar a realidade que percebemos. Isto implica na total responsabilidade pelo que vemos.

A partir disso, ele propõe uma abordagem diante da vida que denomina de Reology: uma mudança paradigmática na maneira como vemos a nós mesmos, levando a novos comportamentos.

Reology aponta para uma nova maneira de se comunicar modificando a linguagem de modo que fica explícito que o mundo que estamos falando é o mundo que percebemos. Trata-se de ReSpeak - que poderíamos traduzir como falar de uma nova maneira, em que assumimos responsabilidade pelo que estamos vendo e sentindo. Para Eagle, a forma que conversamos conosco e com outras pessoas determina a qualidade de nossos relacionamentos. ('The way we talk to ourselves and other people determines the quality of our relationships'. p. 19).

Através de seus ensinamentos, as pessoas são levadas a reorientar suas vidas com o intuito de se relacionar melhor com os outros e com eventos, na medida em que conhecem mais sobre si mesmas, assumindo radical responsibility (responsabilidade radical) por suas vidas.

\section{ReSpeak - nova forma de falar}

ReSpeak consiste numa maneira de falar diferente da usual. É uma forma de se expressar em que nos tornamos conscientes de que somos nós que atribuímos sentido ao mundo que configuramos. Nesta linguagem, assumimos que somos a fonte de nossos sentimentos e percepções.

Dito de outro modo, a linguagem é uma ferramenta para tomarmos consciência de que somos os autores de nossas vidas. Quando praticamos ReSpeak, ao conversamos ou ao relatar um caso, nós nos damos conta da autoresponsabilidade pelo modo como percebemos e sentimos. Ao praticarmos esta nova maneira de falar, transmutamos substantivos em verbos. Por exemplo, ao invés de dizer: estou com raiva, dizemos: estou me fazendo raivosa.

A formação na língua portuguesa não é tão fácil como na inglesa. Em inglês substituímos I am angry, por I angry myself. Creio que o importante é a consciência do processo perceptivo que, necessariamente, leva a um maior conhecimento de si. Entretanto, o uso desta 'linguagem' é um lembrete constante da autoresponsabilidade pelo que se vê e pelo que se sente.

Há a compreensão de que quando falamos, o fazemos a partir de nossa percepção, ao invés de considerarmos que estamos lidando com fatos. Desta forma, não podemos lançar mão de 'fatos' para considerar as pessoas erradas (p.28). Quando falamos, sempre falamos de nossas percepções do mundo. 
Segundo Jake Eagle, há duas maneiras de falar, independente do conteúdo: ou reconhecemos nosso poder de interpretação dos eventos e assumimos que somos os geradores de significado do mundo. Ou, falamos como se fôssemos vítimas de pessoas e eventos. Ele pergunta: você fala do impacto que o mundo causa em você ou como você causa impacto no mundo? (Do you talk about the world impacting you, or about how you impact the world? p.32). E, na fala, também é considerado se estamos apegados ao passado e futuro ou se vivemos no momento presente.

Então, ele recomenda uma nova maneira de falar na qual ficamos mais conscientes de nossos sentimentos e valores, em que tomamos o poder de nossas vidas em nossas mãos e vivemos no momento presente.

ReSpeak tem duas regras básicas: retorno ao agora e remoção da culpa e do elogio. Retorno ao agora implica em conversar sobre o que está acontecendo no momento presente. Ele afirma que se nos perdemos no passado ou nas fantasias do futuro, perdemos a capacidade de perceber as situações com precisão, o que significa que nossas respostas/ atos, provavelmente não serão apropriados.

Remoção de elogios e culpas é o reconhecimento que não há algo independente de nós a quem elogiar ou acusar: estes acontecem a partir de nossas interpretações. Elogio e acusação são resultados de nossa maneira de olhar para o outro e para os acontecimentos.

Para Eagle, acusações e elogios servem para controlar as pessoas. Além disto, estão baseados na dicotomia entre bom e ruim - algo que ele desconhece como existindo de per se. Esta dualidade gera dependência. Nós nos tornamos dependentes de elogios a fim de nos sentirmos bem conosco. E leva também ao fortalecimento de defesas psíquicas que acontecem quando temos medo do julgamento, quando vem na forma de culpabilização.

Eagle estabelece uma diferença entre elogio e apreciação: no elogio, você diz ao outro o que ele é. Na apreciação, você diz ao outro qual sua experiência na relação com ele.

ReSpeak propicia a possibilidade de nos libertarmos da dependência de outro para nos sentirmos bem. Trata-se de uma linguagem - se podemos nos referir assim - em que somos responsáveis por nossos sentimentos e pelo que estamos fazendo conosco no presente momento. Sempre leva em consideração a pergunta: o que estou fazendo comigo? (What am I doing to myself? p.43)

\section{Diretrizes da nova fala}

Este modo de falar compreende duas diretrizes: a primeira é 'resource our feelings' - o que significa considerar a fonte de nossos sentimentos. De acordo com a filosofia que fundamenta 
ReSpeak, a fonte de nossos sentimentos se encontra em nosso próprio ser. Deste modo, assumimos que nosso modo de sentir e a forma como o mundo se apresenta para nós depende de nós. Eagle escreve: "I own my feelings and inner experiences..." own significa possuir, tornar nosso.

Quando substituímos a injunção 'você me causou frustração', por 'eu frustrei a mim mesmo', mudamos o sentido do que vivemos. Ao reconhecermos a fonte do sentimento como nossa , mudamos a forma como vivemos a experiência. Além disso, quando transformamos os substantivos em verbos, geramos um estado dinâmico ao invés de estático: I am annoyed - eu estou aborrecido; I annoy myself (eu aborreci a mim mesmo ,produzi esta aborrecimento em mim), supõe que estou assim neste momento presente.

Jake coloca que o sentimento acontece em nós, então somos nós que possuímos o sentimento. "The feeling occurs in me, so I own the feeling" (p.44) -. Como exemplo, ao invés de falar - I am delighted with this, eu digo: I delight myself with this (Estou satisfeito com isto, eu satisfaço a mim mesmo com isto).

Isto tem duas implicações: o sentido de que estamos em processo, não é algo fixo e a assunção do sentimento como algo que somos nós que estamos causando a nós mesmos. Ele recomenda substituir a partícula it em inglês pelo pronome $I(\mathrm{eu})$. Na medida em que fazemos isto fica cada vez mais claro que somos nós que atribuímos significado aos acontecimentos e às atitudes dos outros.

De acordo com Jake Eagle, ao usar a linguagem desta maneira, nós nos apoderamos de nós mesmos, ninguém está fazendo 'coisas' conosco. Deixamos de ser vítimas para sermos árbitros de nossas vidas.

A concepção ordinária que temos de nossas emoções é que sentimos da forma como sentimos por causa do outro - o outro nos causa determinados estados de espírito em nós. A orientação do Reology é de nos libertarmos da dependência do outro - seja para nos sentirmos bem, seja para nos sentirmos mal. Resgatamos nosso poder de volta.

Esta orientação terapêutica leva a uma libertação. Reconhecemos que nossos estados de espírito não são causados por outros, mas por nós. Normalmente, nos sentimos mal e achamos que o outro é a causa de nossa tristeza, raiva ou depressão. Mas, nesta abordagem, nos damos conta que somos nós a fonte do que sentimos e somos nós os responsáveis por agir da forma que agimos - seja em relação aos outros ou a nós mesmos. Deixamos de ser marionetes nas mãos dos outros, deixamos de ficar à mercê dos acontecimentos. Podemos escolher como queremos estar.

Importante, então, nos darmos conta de que temos possibilidade de escolhas. Diante de situações desafiadoras, podemos escolher a como responder - podemos ser reativos ou nos tornar curiosos - procurar questionar porque a pessoa disse o que disse ou se comportou de determinada maneira. 
A outra diretriz diz respeito a respeitarmos as diferenças entre nós. Se reconhecemos que nunca estamos falando sobre um evento em si mesmo, mas estamos sempre nos referindo á nossa percepção, então é cabível levar em conta a interpretação do outro. Devemos, portanto, respeitar o modo diferente de como as pessoas percebem os eventos. Isto tem como consequência abolirmos a ideia de que o outro está errado. Não se trata de estar errado, mas de ter percebido o mesmo evento de maneira diferente. O outro tem outro olhar, outra visão, apenas isto.

Este são pilares do ReSpeak, o reconhecimento disto elimina muitas discussões desnecessárias e fomenta a paz. Com esta compreensão, desaparece o desejo de fazer com que o outro esteja errado origem de muitos conflitos.

A pedra angular, vale repetir, é a aceitação de que tudo o que observamos é observado através de nossos filtros pessoais. Nas palavras de Jake: Tudo que observamos é observado através de nossos filtros pessoais. ('everything we observe is seen through our personal filters p.46).

Trata-se, portanto, de uma mudança revolucionária na visão e portanto, no modo de estar no mundo. Pois nossas condutas são resultantes do modo como percebemos as pessoas e acontecimentos. Trata-se de uma mudança paradigmática da percepção.

A linguagem se modifica então, porque já não mais afirmamos: fulana é assim - como se falássemos de algo objetivo, mas falamos : É assim que vejo esta pessoa; ou ao invés de dizer : 'isto é desta maneira", falamos: Esta é a maneira é como vejo isto". Isto porque não podemos refletir algo objetivo do mundo, tudo o que podemos fazer é comunicar como vemos o mundo. (we can't convey an objective reflection of the world, we can only convey how we see the world. p.47).

Jake Eagle sugere 5 passos para a mudança de atitude quando percebemos um sentimento ou situação como desagradáveis, ou que tiram nosso equilíbrio: tomada de consciência, aceitação, autoindagação, espera e ação.

Quando, por exemplo, nos sentimos frustrados, primeiro temos que nos dar conta deste sentimento em nós. é fundamental que estejamos conscientes de nossos sentimentos, desejos e pensamentos. O segundo passo consiste em assumir que somos nós que estamos fazendo isto a nós mesmos, ou seja. nós estamos nós frustrando (somos responsáveis pelo modo como sentimos, somos os autores de nosso mundo). E reconhecemos que se há algo que quereremos ou necessitamos e que não temos.

A partir do reconhecimento de que algo está faltando, fazemos perguntas chaves: - o que quero, como eu gostaria de estar me sentindo agora?. Como devo me conduzir ou pensar de modo a me sentir melhor? Esperamos um pouco, nos presentificando em nosso ser. Eagle coloca o tempo de espera como a consciência entre o modo como estamos nos sentindo e como gostaríamos de nos sentir. E, se for o caso, tomamos atitudes para modificar a situação. É importante que saibamos quais são nossas necessidades e procurarmos maneiras saudáveis de satisfazê-las ( vide p. 60). 
É fundamental, nesta compreensão de nosso agir e estar que aceitemos que somos nós os 'construtores' de nós mesmos, e que portanto, podemos nos construir de modo diferente. Esta é nossa liberdade. O modo como estamos nos sentindo: alegres, tristes , frustrados, depressivos, - cada um destes estados de espírito consistem no modo como estamos determinando que sentimos, como estamos escolhendo nos sentir. Se somos nós a fonte de nossos sentimentos, podemos modificá-los. Podemos usar nossa energia de modo a nos sentir melhor.

\section{Responsabilidade e Vitimismo}

Ao não responder por nossos sentimentos e ações, jogamos a responsabilidade no outro. Isto leva ao sentimento de vítima. Nós nos sentimos vítimas do outro. E aí dizemos ao mundo - veja o que ele fez comigo!

A acusação é, exatamente, uma falta de responsabilidade com a própria vida. Acusamos o outro por nos sentirmos de determinada maneira. Esta é uma concepção de mundo em que o foco está no exterior. Cremos que é o mundo externo direciona nossa vida. Eu diria que esta concepção de mundo não se restringe apenas a eventos negativos - nosso foco está fora, sempre achamos que são acontecimentos ou pessoas externas a nós que nos fazem sentir alegres ou tristes.

Quando mudamos o foco do externo para o interno, reconhecemos que nós temos o poder de escolher como reagir, qual sentimento ter em relação ao evento. Ao nos darmos conta de que somos nós os 'construtores' de nossa vida, tomamos o poder em nossas mãos, nossos estados de espírito não ficam mais dependentes dos outros.

Responsabilidade é o oposto do vitimismo. Quando somos responsáveis somos poderosos, temos o poder em nossas mãos, quando projetamos, acusamos o outro, somos vítimas, somos bonecos nas mãos dos outros. Não assumir a responsabilidade por nosso ser, necessariamente se desdobra em acusar o outro. O outro é que é o responsável. Isto acontece através da projeção.

Jake afirma que, na medida em que assumimos mais responsabilidade experimentamos menos sofrimento. Com suas palavras: A medida em que não assumimos responsabilidade é a medida em que vitimamos a nós mesmos. Quando nós nos sentimos vítimas, damos desculpas e acusamos os outros. Sempre que acusamos as pessoas, nós não estamos assumindo responsabilidade por nossas próprias experiências ou nossos próprios sentimentos. Outras pessoas vêm a ser o que nos despista e então não temos que examinar o que fizemos para criar a confusão em que estamos. ('the degree to which we don't take responsibility is the degree to which we may victimize ourselves. When we experience ourselves as victims we make excuses and blame other people. Whenever we blame other people, we aren't taking responsibility for our own experiences or our own feelings. Other people 
become a distraction so that we don't have to examine our contribution to creating the mess we're in." p.121)

Não é raro escondermos algo que não gostamos em nós mesmos. Então, projetamos em alguém o modo como sentimos ou mesmo, como pensamos. A projeção é um modo de negar para nós qualidades que não admitimos como nossas. É uma maneira de esconder-se.

É muito usual projetarmos falhas, culpas nos outros. Ao lançarmos a culpa em outra pessoa, nós fugimos de nós mesmos. Trata-se de uma forma de não assumir determinados sentimentos, por exemplo.

Portanto, a projeção acontece quando não assumimos nosso ser, nossas qualidades e defeitos. É uma irresponsabilidade quanto aos nossos atos e sentimentos. Não aceitamos, negamos, lançamos para fora. Não respondemos às nossas emoções como sendo nossas. Deste modo, somos irresponsáveis.

Assim, projetamos a origem, a fonte de nossos sentimentos no outro. Fazemos isto sem nos dar conta. Ao agirmos desta maneira, ficamos mais longe de nosso próprio ser, nos alienamos de nós. E, também, perdemos a capacidade de estabelecer uma ligação com o outro. A projeção instiga a separação, nos impede de nos conectar com o outro, pois quando projetamos uma qualidade negativa, nos afastamos das pessoas a quem atribuímos falhas, a quem consideramos estarem errados.

Não assumir a responsabilidade por nossos sentimentos é um caminho mais fácil, porque é difícil aceitar sentimentos ruins como nossos. Sentimos raiva e justificamos nossa raiva afirmando que foi o outro que nos fez ficar com raiva. Dizemos: 'estou com raiva por causa de fulano, ou porque tal coisa nos aconteceu'. A acusação é uma maneira de justificar a própria raiva. - Nós nos desapropriamos de nosso sentimento.

Relacionamentos saudáveis requerem autoconhecimento. Se não formos profundamente conhecedores de nossos sentimentos e necessidades, vamos projetá-los nos outros, gerando conflito e afastando-nos deles. Precisamos estar alertas para nossas experiências internas a fim de mantermos relacionamentos mais harmoniosos.

Isto leva à questão da honestidade. É conosco que precisamos ser honestos: quais são nossos valores, desejos, sentimentos e necessidades. Quando estamos conectados conosco, facilmente nos conectamos com os outros. Quando não reconhecemos nossos sentimentos como nossos e quando não reconhecemos nossas necessidade, projetamos os sentimentos e acusamos o outros por nosso sofrimento. Jake afirma que quanto mais estivermos desconectados de nós mesmos, mais sofremos ( ' ...the longer I say disconnected from myself, the more I will suffer. p.118)

É comum pensarmos que honestidade consiste em dizer ao outro o que o outro é. Mas isto é uma impossibilidade. Tudo o que sabemos dos outros são nossas interpretações, nossas percepções. Considero honestidade a capacidade de nos darmos conta de quais são nossos sentimentos, 
necessidades e valores por meio dos quais erigimos a imagem dos outros em nós. Num exemplo bem simples: em vez de dizer que o outro fala baixo, é mais honesto dizer que temos a necessidade de que fale mais alto; em vez de dizer que o outro é agressivo, é honesto dizer que tal comportamento não atende às nossas expectativas, ou que ficamos magoados por algum gesto ou palavra dita. O mesmo gesto ou palavra pode não ter nenhuma repercussão negativa em outra pessoa.

Ao assumirmos a responsabilidade por nossa vida, deixamos de culpar o outro por nossas falhas ou por acontecimentos que consideramos desagradáveis. Isto fomenta a paz e favorece a conexão com as pessoas. Também, invertemos o papel de vítimas para o papel de pessoas de poder. Temos o poder de escolher como nos sentir frente aos acontecimentos. Assumir a responsabilidade por nós, significa um maior conhecimento de si, de nossos estados interiores, nos livrando de rótulos como bom ou mal - o que sentimos é legítimo. E, neste processo ainda temos um mundo de possibilidade sobre o qual navegar. Isto é libertador.

\section{Referências}

EAGLE, Jake. ReRight Your Life: an introduction to Reology Novo México. Editor independente, 2011.

BARNES \& NOBLE, A. A Course in Miracles., Inc., em acordo com A Course in Miracles International, 2007.

PIERRE, Claudia M.M. Culpa, Cura e Relacionamento. São Paulo: Novo Século, 2012.

\section{Como citar esse artigo (ABNT):}

PIERRE, C.M.M. Linguagem e Responsabilidade: Contribuições de J. Eagle para Relacionamentos Saudáveis. Id on Line Revista de Psicologia, Julho de 2014, vol.8, n.23, p. 171-178. ISSN 1981-1179. 